\title{
The Acyl-CoA Synthetase Inhibitor Triacsin C Enhanced Eicosanoid Release in Leukocytes
}

\author{
Sachiko Oh-ishi, Kohji Yamaki, Mitsuhiro Abe, Hiroshi Tomoda ${ }^{1}$ and Satoshi Ōmura ${ }^{1}$ \\ Department of Pharmacology, School of Pharmaceutical Sciences, Kitasato University, and 'Kitasato Institute, \\ 5-9-1, Shirokane, Minato-ku, Tokyo 108, Japan \\ Received March 19, 1992 Accepted April 24, 1992
}

\begin{abstract}
Triacsin C was previously reported to inhibit long-chain acyl-CoA synthetase and to reduce the production of acyl-CoA in rat neutrophils dose- and time-dependently. We found that preincubation with triacsin $\mathrm{C}$ inhibited the incorporation of labeled arachidonic acid into rat neutrophils. Furthermore, when triacsin C-treated neutrophils were stimulated with the Ca-ionophore A23187, they released an increased amount of eicosanoids into the culture medium. These results indicate that triacsin C suppressed acylation of arachidonic acid, which resulted in an increase in its metabolites.
\end{abstract}

Keywords: Triacsin C, Acyl-CoA synthetase, Arachidonic acid

Triacsin C (1-hydroxy-3-( $E, E, E-2^{\prime}, 4^{\prime}, 7^{\prime}$-undecatrienylidine) triazene) was discovered in the culture broth of Streptomyces sp. $S K-1894$ and recently reported to be an inhibitor of long-chain acyl-CoA synthetase (1-3). In the previous study, the inhibitory effect of triacsin C on oleoyl-CoA synthetase in rat neutrophils was examined by incubation with ${ }^{14} \mathrm{C}$-labeled oleic acid and $\mathrm{CoA}$ in the presence of triacsin $\mathrm{C}$. The production of labeled oleoyl-CoA was reduced as the concentration of triacsin $\mathrm{C}(1-500 \mathrm{nM})$ was increased, and the inhibition reached a plateau after $60 \mathrm{~min}$. However, the agent did not inhibit acetyl-CoA synthetase $(3,4)$.

In this paper, we report the effect of triacsin $\mathrm{C}$ on the incorporation of arachidonic acid into rat peritoneal polymorphonuclear leukocytes and also its effect on the release of arachidonic acid and its metabolites.

The leukocytes were collected from peritoneal washings of casein-treated rats $16 \mathrm{hr}$ after the intraperitoneal injection of $30 \mathrm{ml}$ of $1 \%$ casein solution, as previously reported (5). The leukocytes thus collected were mostly neutrophils $(85-88 \%)$. First, we examined the effect of triacsin $\mathrm{C}$ on the incorporation of exogenous arachidonic acid. The rat neutrophils $\left(5 \times 10^{7}\right.$ cells $\left./ \mathrm{ml}\right)$ were incubated with triacsin $\mathrm{C}(0,50$, or $500 \mathrm{nM})$ for 60 min (inhibition of acyl-CoA synthetase was almost at the plateau level after preincubation for $60 \mathrm{~min}$ (3)), and then further incubated with ${ }^{14} \mathrm{C}$-arachidonic acid (Amersham Japan; $2.16 \mathrm{GBq} / \mathrm{mmol}, 0.223 \mu \mathrm{M}$ ) in Hanks' balanced salt solution (HBSS) for $20 \mathrm{~min}$ at $37^{\circ} \mathrm{C}$. The reaction was terminated by centrifugation, and radioactivity incorporated in the cells was counted. The result is shown in Fig. 1. Labeled arachidonic acid

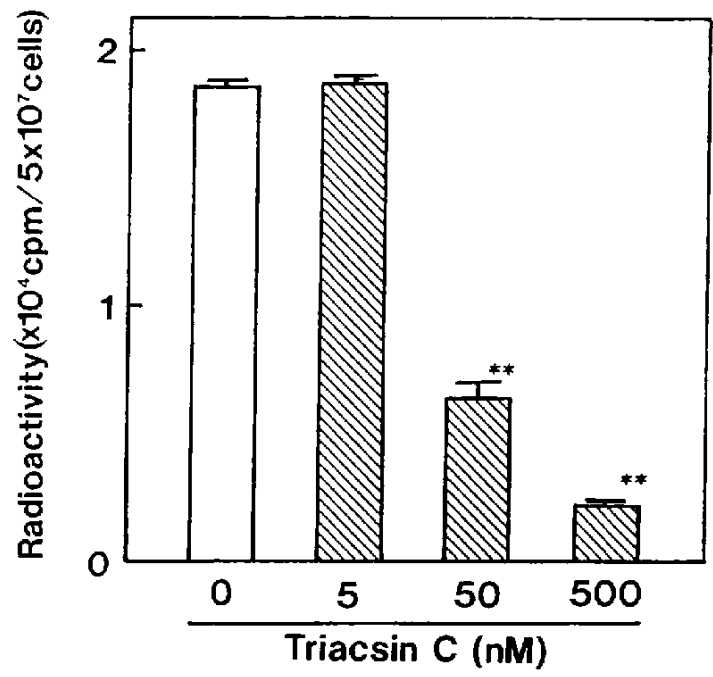

Fig. 1. Effect of Triacsin $\mathrm{C}$ on the incorporation of ${ }^{14} \mathrm{C}$-arachidonic acid in rat polymorphonuclear leukocytes. Casein-stimulated rat peritoneal neutrophils were collected, incubated $\left(5 \times 10^{7}\right.$ cells $/ \mathrm{ml})$ with triacsin $\mathrm{C}(0,5,50,500 \mathrm{nM})$ for $60 \mathrm{~min}$, and then incubated in the presence of ${ }^{14} \mathrm{C}$-arachidonic acid $\left(0.223 \mu \mathrm{M},{ }^{14} \mathrm{C}\right.$ label, $2.16 \mathrm{GBq} / \mathrm{mmol}$ ) for $20 \mathrm{~min}$. Radio-activity incorporated into the cells was counted. Values are means of 4 experiments with standard deviations. ${ }^{* *}$ indicates the value is significantly different $(P<0.01)$ from the control value without triacsin $C$. 
Table 1. Release of arachidonic acid and its metabolites from rat neutrophils when stimulated with A23187

\begin{tabular}{lrrrrr}
\hline & \multicolumn{1}{c}{0} & \multicolumn{2}{c}{ Triacsin $(\mathrm{nM})$} & \multicolumn{1}{c}{500} \\
\hline Arachidonic acid & $12.4 \pm 1.4$ & & $26.0 \pm 2.7$ & $113.3 \pm 13.5^{*}$ & $156.8 \pm 2.2^{*}$ \\
5-HETE & $358.6 \pm 16.6$ & $399.0 \pm 19.6$ & $648.0 \pm 22.2^{*}$ & $666.2 \pm 28.5^{*}$ \\
6-keto-PGF - $_{10}$ & $11.7 \pm 1.7$ & $17.9 \pm 2.9$ & $18.7 \pm 3.6$ & $30.5 \pm 1.0^{*}$ \\
PGE $_{2}$ & $5.6 \pm 0.6$ & $6.4 \pm 0.8$ & $10.5 \pm 0.3^{*}$ & $16.6 \pm 0.4^{*}$ \\
\hline
\end{tabular}

Amounts of arachidonic acid and its metabolites arc expressed as means with standard deviations of 3 experiments as $\mathrm{ng} /\left(4 \times 10^{7}\right.$ cells $)$. Rat neutrophils were preincubated with the indicated concentrations of triacsin $\mathrm{C}$ for $60 \mathrm{~min}$ and then stimulated with $12.5 \mu \mathrm{M}$ Cd-ionophore $\mathrm{A} 23187$ for $5 \mathrm{~min}$. ${ }^{*}$ indicates that the values are statistically significantly different $(\mathrm{P}<0.05)$ from the control value $(0 \mathrm{nM})$ by Dunnett's $t$-test.

incorporation was significantly $(\mathrm{P}<0.01)$ and dose-dependently suppressed by the pretreatment with triacsin C. This result suggests that acylation of arachidonic acid may also be inhibited by triacsin $C$.

Next we examined the effect of triacsin $\mathrm{C}$ on the release of arachidonic acid and its metabolites. The rat neutrophils were incubated in HBSS for $60 \mathrm{~min}$ in the presence of triacsin $\mathrm{C}(0-500 \mathrm{nM})$, and then they were incubated without or with $12.5 \mu \mathrm{M}$ Ca-ionophore A23187 for $5 \mathrm{~min}$. The condition for stimulation with A23187 was the same as described in the previous paper (5). Reaction was terminated by centrifugation at $4^{\circ} \mathrm{C}$, and the released products in the supernatant were extracted and assayed by the ADAM-HPLC method as previously described (6). In short, arachidonic acid and its products were extracted through a Sep-pak $C_{18}$ cartridge (Waters, USA), and the methanol eluate was mixed with the solution of $0.2 \% 9$-anthryldiazomethane (ADAM, Funakoshi Pharm. Co., Tokyo) in ethylacetate. The reaction mixture was processed as previously reported and subjected to reversed phase HPLC (6).

Table 1 shows the amounts of released metabolites from rat neutrophils treated with the inhibitor and A23187. The levels were estimated from standard curves and retention times generated with the above authentic standards, which were eluted before or after the samples. The amount of eicosanoids released from the neutrophils without pretreatment with triacsin was almost similar to that reported previously (6). The results indicate that these products increased with the dose of triacsin $\mathrm{C}$ : arachidonic acid increased to a level almost 10 times (at the triacsin dose of over $50 \mathrm{nM}$ ) over that obtained from A23187-stimulated cells that had been preincubated without triacsin $C$, and the arachidonate metabolites (5-HETE, 6-keto- $\mathrm{PGF}_{1 \alpha}$ and $\mathrm{PGE}_{2}$ ) showed a 2-3-fold increase (at $500 \mathrm{nM}$ ). Incubation with triacsin $\mathrm{C}$ alone for $60 \mathrm{~min}$ did not increase the amount of these metabolites (data not shown).

These results indicate that triacsin $C$ suppresses the uptake of arachidonic acid into the leukocytes by inhibiting its acylation via acyl-CoA synthetase. Then this suppression may cause the increased release of arachidonic acid and its metabolites when the leukocytes were stimulated with A23187. The data shown in Fig. 1 could be the resultant effect of inhibition of acyl-CoA synthetase. Thus treatment of rat neutrophils with triacsin C results in the accumulation of free arachidonic acid, and this may in turn serve as precursor source for its metabolites. However, further detailed studies are necessary for the clarification of its mechanism.

\section{REFERENCES}

1 Ōmura, S., Tomoda, H., Xu, Q.M., Takahashi, Y. and Iwai, Y.: Triacsins, new inhibitors of acyl-CoA synthetase produced by Streptmyces Sp. J. Antibiot. (Tokyo) 39, 1211-1218 (1986)

2 Tomoda, H., Igarashi, K. and Ömura, S.: Inhibition of acyl-CoA synthetase by triacsins. Biochim. Biophys. Acta 921, 595-598 (1987)

3 Tomoda, H., Igarashi, K., Cyong, J.-C. and Ōmura, S.: Evidence for an essential role of long chain acyl-CoA synthetase in animal cell proliferation. Inhibition of long chain acyl-CoA synthetase by triacsins caused inhibition of RAJI cell proliferation. J. Biol. Chem. 266, 4214- 4219 (1991)

4 Hayashi, M., Imai, Y., Yamaki, K., Tomoda. H., Ōmura, S. and Oh-ishi, S.: Potentiating effect of triacsin on the biosynthesis of platelet-activating factor in rat leukocytes. Japan. J. Pharmacol. 52, Supp. I, 125P (1990)

5 Yamaki, K. and Oh-ishi, S.: Release of leukotriene $B_{4}$ and 6-keto-prostaglandin $F_{1 \alpha}$ from rat leukocytes in response to platelet-activating factor or Ca-ionophore A23187. J. Lipid Med. 2, 317-327 (1990)

6 Yamaki, K. and Oh-ishi, S.: Comparison of eicosanoids production between rat polymorphonuclear leukocytes and macrophages: Detection by high-performance liquid chromatography with precolumn fluorescence labeling. Japan. J. Pharmacol. 58, 299-307 (1992) 